\title{
LIMA BARRETO EM TRADUÇÃO
}

\section{LIMA BARRETO IN TRANSLATION}

Denise Bottmann

Pesquisadora autônoma São Paulo, São Paulo, Brasil

RESUMO: $O$ presente artigo traz o levantamento bibliográfico das traduções da obra de Lima Barreto publicadas em livro, de 1946 a 2017, em diversos países. Seu objetivo é fornecer uma base de dados para pesquisadores da área, servindo como compilação consolidada de informações primárias até então dispersas em várias fontes.

PALAVRAS-CHAVE: Lima Barreto; traduções; literatura brasileira no exterior

\begin{abstract}
This paper provides a bibliographic survey of Lima Barreto's works translated from Portuguese into other languages and published as books in several countries from 1946 to 2017. The aim of the paper is to be useful as an archive for researchers, who will find gathered within it a significant amount of primary data previously scattered across several sources.
\end{abstract}

KEYWORDS: Lima Barreto; translations; Brazilian literature outside Brazil 


\section{SEÇÃO I: Dados e breves considerações1}

Aqui apresento toda a bibliografia barretiana em tradução, publicada em livro, que me foi possível apurar. Em que pesem inevitáveis lacunas e omissões, este levantamento certamente abrange a grande maioria das publicações de obras de Lima Barreto em língua estrangeira, em livro físico e/ou digital.

O arrolamento está disposto em ordem alfabética de idioma e, dentro de cada idioma, por ordem cronológica da primeira edição.

\subsection{Alemão}

Lateinamerika erzählt. Org. Albert Theile. Contém "Der Mann, der Javanisch konnte" [O homem que sabia javanês]. Frankfurt am-Main: Fischer, 1962.

Brasilien erzählt. Org. Inês Koebel. Contém "Neu-Kalifornien" [A nova Califórnia]. Frankfurt am-Main: Fischer, 1994.

Das Traurige Ende des Policarpo Quaresma. Tradução Berthold Zilly. Zurique: Amman, 2001.

Der blaue Affe und andere brasilianische Erzählungen. De Lima Barreto contém, entre outros contos, "Der pan-planetarische Kongress" [Congresso panplanetário"] e "Der Mann, der Javanisch konnte". Tradução Ulrike Jürgens. Viena: Sonderzahl-Verlag, 2013.

Brasilien erzählt. Contém "Der Mann, der Javanisch konnte". Coleção Fischer Taschen Bibliothek. Fischer-Verlage, 2013.

\subsection{Catalão}

El trist final d'en Policarpo Quaresma. Tradução Josep Domènech Ponsatí. Martorell: Adesiara, 2017.

\footnotetext{
${ }^{1}$ Partes dos dados aqui apresentados encontram-se publicados na página da FLIP, no seguinte endereço: < http://flip.org.br/edicoes/flip-2017/noticias/lima-barreto-ja-estadisponivel-em-15-idiomas-segundo-levantamento-feito-por-denise-bottmann $>$
} 


\subsection{Chinês}

会爪哇语的人 [Huì zhăowāyǔ de rén: O homem que sabia javanês]. Tradução do grupo de mestrado em Estudos de Tradução, coord. Raquel Abi-Sâmara. Macau: Universidade de Macau/ Consulado do Brasil, MRE, 2012.

\subsection{Espanhol}

Primera antología de cuentos brasileños. Sel. Braulio Sánchez Sáez. Contém "El hombre que sabía javanés". Colección Austral, 596. Buenos Aires: Espasa-Calpe, 1946.

Pequeña antologia de cuentos brasileños. Sel. Marques Rebelo. Contém "El hombre que sabía javanés". Tradução Raúl Navarro. Colección Mar Dulce. Buenos Aires: Nova, 1946.

Los mejores cuentos americanos. Sel. Aníbal Quijano. Contém "El hombre que sabía javanés". Coleção Malicha. Lima: Juan Mejía Baca \& P.L. Villanueva, [1955].

Dos Novelas: Recuerdos del escribiente Isaías Caminha - El Triste Fin de Policarpo Quaresma. Tradução Haydée M. Jofre Barroso. Caracas: Biblioteca Ayacucho, 1978.

Cuentos brasileños del siglo XX: antología bilíngue. Contém "El hombre que sabía javanés". Tradução Manuel Graña Etcheverry. Buenos Aires: Colihue, 1996.

Antologia de cuentos brasileños. Sel. e tradução José Luis Sánchez. Contém "El hombre que sabía javanés". Rio de Janeiro: Biblioteca Nacional, 2004.

Vereda tropical: antologia del cuento brasileño. Sel. Maria Antonieta Pereira. Contém "La nueva California". Buenos Aires: Corregidor, 2005.

Recuerdos del escribano Isaías Caminha. Tradução Javier Díaz Noci. Bilbao: Universidad del País Vasco, Servicio Editorial, 2007.

Los bruzundangas: una sátira politica. Tradução Ezequiell Bajder. Buenos Aires: Vestales, 2008.

La nueva California y otros cuentos. Tradução Pablo Roca. Montevidéu: Banda Oriental, 2008.

El triste fin de Policarpo Quaresma. Buenos Aires: Mardulce, 2012. 
El cementerio de los vivos. Tradução Victor David López e Aline Pereira da Encarnação. Madri: Ediciones Ambulantes, 2014.

Los Bruzundangas. Tradução Juan Bautista Rodríguez Aguilar. Pozuelo de Alarcón: Rapsoda, 2016.

\subsection{Esperanto}

La Homo, kiu scipovis la javan lingvon [O homem que sabia javanês]. Tradução Paulo Sergio Viana. Lorena: Lorena Esperanto-klubo, 2009.

\subsection{Francês}

Fleur, téléphone et jeune fille et autres contes brésiliens. Contém "Son excellence". Tradução Catherine Orfila. Edição bilíngue. Paris: l'Alphée, 1980.

Souvenirs d'un Gratte-Papier [Recordações do escrivão Isaías Caminha]. Tradução Monique Le Moing e Marie-Pierre Mazeas. Coleção L'Autre Amérique. Paris: L'Harmattan, 1989.

Sous la Banniere Etoilèe dela Croix du Sud [O triste fim de Policarpo Quaresma]. Tradução Monique Le Moing e Marie-Pierre Mazeas. Coleção L'Autre Amérique. Paris: L'Harmattan, 1992.

Vie et Mort de Gonzaga de Sá. Tradução Monique Le Moing e Marie-Pierre Mazeas. Coleção L'Autre Amérique. Paris: L'Harmattan, 1994.

Un Amer Tourment et Trois Autres Contes. Tradução Monique Le Moing. Coleção Pour une Fontaine de Feu. Cherves: Rafael de Surtis, 1998.

Le Fils de Gabriela et Deux Autres Contes. Tradução Monique Le Moing. Coleção Pour une Fontaine de Feu. Cherves: Rafael de Surtis, 1998.

La Nouvelle Californie et Trois Autres Contes. Tradução Monique Le Moing. Coleção Pour une Fontaine de Feu. Cherves: Rafael de Surtis, 1999.

L'Homme qui parlait javanais et autres nouvelles. Contém: "L'homme qui parlait javanais"; "Livia"; "Son excellence"; "Adélia"; "Mon carnaval"; "Cló". Tradução Monique Le Moing. Edição bilíngue. Paris: Éditions Chandeigne, 2012. 


\subsection{Grego}

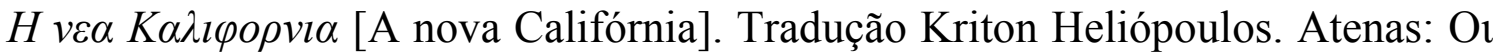
Ekdoseis tōn sunadélphōn [2014].

\subsection{Inglês}

The Borzoi Anthology of Latin American Literature. Org. Emir Rodríguez Monegal e Thomas Colchie. Contém "The sad end of Policarpo Quaresma". Tradução Gregory Rabassa. Nova York: Knopf, 1977.

The Patriot [Triste fim de Policarpo Quaresma]. Tradução Robert Scott Buccleuch. Londres: Collings, 1978.

Lima Barreto, bibliography and translations. Org. Maria Luísa Nunes. Contém "Clara dos Anjos", tradução Earl E. Fitz; e "Life and Death of M.J. Gonzaga de Sá”, tradução Rosa Veloso Dwyer e John P. Dwyer. Boston: G. K. Hall, 1979.

The Oxford Book of Latin American short stories. Org. Roberto Gonzalez Echevarria. Contém "The man who knew Javanese". Tradução Gregory Rabassa. Nova York: Oxford University Press, 1999.

Oxford Anthology of the Brazilian Short Story. Org. K. David Jackson. Contém "The man who knew Javanese". Tradução Clifford E. Landers. Oxford: Oxford University Press, 2006.

The sad end of Policarpo Quaresma. Tradução Mark Carlyon. Coleção River of January. Edição bilíngue. Rio de Janeiro: Cidade Viva, 2011. [Reed. Londres: Penguin, 2014.]

The tragic death of Policarpo Quaresma. Tradução Luciano Beck. IBooksFromBrazil, e-book, 2012.

Tales from Old Brazil, vol. 1. Contém "The library"; "The man who spoke Javanese"; "Late bet"; "Good idea"; "Burials at Inhaúma". Sel. e tradução Francis K. Johnson. Coleção Brazilian Classics. Kindle edition, 2013.

The decline and fall of Policarpo Quaresma. Tradução Francis K. Johnson. Coleção Brazilian Classics. Kindle edition, 2014. 


\subsection{Italiano:}

Policarpo Quaresima. Tradução Ombretta Borgia e Sergio Magaldi. Roma: Pericle Tangerine, 2004.

Il cimitero dei vivi. Tradução S. Marianecci. Roma: Azimut, 2007.

Nella terra di Bruzundanga. Cronache dal Brasile. Coleção Gli eccentrici. Salerno: Arcoiris, 2013.

Clara dos Anjos. Tradução R. Santini e F. Gurgone. Coleção Al Buon Corsiero. Milão: Diabasis, 2013.

\subsection{Japonês}

Brasirú bungaku tainhen chú [Antologia do conto brasileiro]. Contém: Java gowo shaberú otoko [O homem que sabia javanês]. Tradução Hirokawa Kazuko. Tóquio: Shinshe Kaisha, 1977.

\subsection{Polonês}

Smutny konied Polikarpa Quaresmy [Triste fim de Policarpo Quaresma]. Tradução Janina Zofia Klave. Cracóvia: Wydawnictwo Literackie, 1984.

\subsection{Romeno}

Tristul sfirşit al lui Policarpo Quaresma [Triste fim de Policarpo Quaresma]. Tradução Alexandru Lincu. Bucareste: Sturion, 1991.

\subsection{Russo}

Записки Архивариуса [Recordações do escrivão Isaías Caminha]. Moscou: Художественная литература [Literatura de Ficção], 1965.

Зщздисфкзщ Йгфкуыььф [Triste fim de Policarpo Quaresma]. Moscou: Symposim, 2017. 


\subsection{Sueco:}

Den blodiga midsommarnatten och andra berättelser från Latinamerika. Contém "Ett Nytt Kalifornien" [A nova Califórnia]. Tradução Arne Lundgren. Estocolmo: Fabian, 1988.

\subsection{Tcheco}

Smutný konec snazivého Policarpa [Triste fim de Policarpo Quaresma]. Tradução Jarmila Vojtísková. Praga: Odeon, 1974.

Existe uma tradução para o islandês, feita por Luciano Dutra, porém ainda inédita. $\mathrm{Na}$ rede encontram-se algumas traduções ou compilações avulsas, disponíveis apenas em sites ou blogs, como, por exemplo, Cuentos del Brasil em $<$ https://goo.gl/CE7emS $>$.

II.

Agora, detendo-nos brevemente nos dados apurados sobre as edições publicadas em formato de livro físico e/ou digital, podemos esboçar o seguinte quadro:

Publicações: Encontram-se 50 volumes com obras de Lima Barreto em tradução.

Idiomas: As traduções de obras de Lima Barreto se encontram em 15 idiomas.

Distribuição das publicações por idioma:

Alemão: 5

Catalão: 1

Chinês: 1

Espanhol: 13

Esperanto: 1

Francês: 8

Grego: 1

Inglês: 9

Italiano: 4

Japonês: 1

Polonês: 1

Romeno: 1

Russo: 2

Sueco: 1

Tcheco: 1 


\section{Antologias:}

Desses 50 volumes, cerca de um terço consiste em antologias com vários autores, na seguinte distribuição:

- Alemão: 4

- Espanhol: 6

- Francês: 1

- Inglês: 4

- Japonês: 1

- Sueco: 1

\section{Obras de tradução mais frequente:}

- Triste fim de Policarpo Quaresma conta com quinze traduções nos seguintes idiomas: alemão, catalão, espanhol (2 traduções), francês, inglês (5), italiano, polonês, romeno, russo e tcheco

- O homem que sabia javanês conta com quinze traduções nos seguintes idiomas: alemão (3 traduções), chinês, espanhol (5), esperanto, francês, inglês (3), japonês

Entre os 15 idiomas que contam com traduções da obra de Lima Barreto, destacam-se o espanhol, com 13 publicações, o inglês, com 9, e o francês, com 8 . O inglês apresenta a peculiaridade de contar, entre suas 9 publicações, com nada menos que 5 traduções diferentes de Triste fim de Policarpo Quaresma. Repetição similar ocorre no alemão: com apenas 5 publicações - e quatro delas sendo em antologias com vários autores -, temos nada menos que 3 traduções diferentes de $O$ homem que sabia javanês. E mesmo em espanhol, idioma que conta com maior número de publicações de Lima Barreto (13), cinco das seis antologias de vários autores trazem sempre esse mesmo conto, ainda que em traduções diferentes. Note-se também que 3 línguas entre 15 respondem por 30 lançamentos entre 50. Ou seja, em síntese, vemos no conjunto das traduções uma alta concentração de poucas obras e em poucas línguas.

Nesse contexto, destaca-se a divulgação de Lima Barreto na França. Pois, entre os idiomas com maior número de publicações, o espanhol, evidentemente, distribui-se entre vários países (Argentina, Uruguai, Venezuela, Peru, Espanha); o inglês se distribui entre Inglaterra, EUA e Brasil; somente as publicações em francês se concentram mesmo na França. E é o idioma em que a obra de LB foi traduzida com maior variedade de títulos e de maneira mais sistemática. Monique Le Moing, a tradutora e responsável pela seleção e organização dos volumes quando são de contos, está presente em 7 das 8 publicações francesas, desde 1989 a 2012 .

\section{Distribuição temporal:}


Outro aspecto que merece atenção é a distribuição das publicações ao longo do tempo. Tomando como marco inicial o ano de 1946, na Argentina, em que se têm dois lançamentos de duas antologias diferentes de vários autores, e chegando a 2017, com os recentes lançamentos de mais dois Policarpo Quaresma (agora em catalão e em russo), vemos que, das 50 publicações, 24 foram lançadas no século XX, ao longo de 54 anos, e 26 saíram no século XXI, ao longo de 17 anos.

Em conclusão, são vários os fatores que se podem inferir ou conjeturar a partir de tais dados, abrindo várias perspectivas de novas pesquisas sobre a presença de Lima Barreto no exterior. século XXI.

$\mathrm{O}$ que fica claro é que Lima Barreto nunca esteve tão vivo quanto no

\section{Fontes consultadas}

Bibliotecas Nacionais internacionais

Fundação Biblioteca Nacional

WorldCat

Sites de editoras e sebos internacionais

"Bibliografia, Obras traduzidas", estabelecida por Luiz Antônio de Souza, in Lima Barreto, A.H., Triste fim de Policarpo Quaresma, edição crítica, coord. Antônio Houaiss e Carmen Lúcia Negreiros. Colección Archivos 30. ALLCA XX, 1997.

"Traduções", in Barbosa, Francisco de Assis, A vida de Lima Barreto. 11'. ed. Belo Horizonte: Autêntica, 2017.

Pesquisas gerais no Google

\section{Agradecimentos}

Deixo aqui meus agradecimentos a Marina Ernst por informações sobre a edição

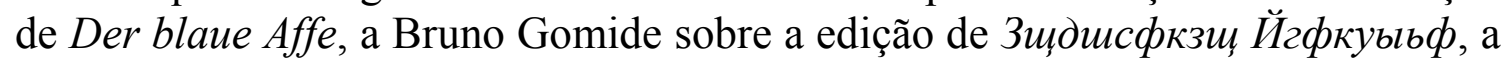
Rafael Brunhara pela transliteração do russo, a Marcelo Barbão pela transliteração do chinês, a Luciana Hidalgo pela troca de ideias e a Josélia Aguiar pela constante inspiração. 
SEÇÃO II: ICONOGRAFIA

Seguem-se abaixo as imagens de capa dos volumes em primeira edição arrolados neste levantamento, sempre que foi possível localizá-las. Vale lembrar o pioneiro levantamento iconográfico das obras traduzidas de Lima Barreto, realizado por Rodrigo Conçole em 2013-14, disponível em $<\underline{\text { https://goo.gl/DzusCo }}>$.

\subsection{Alemão}
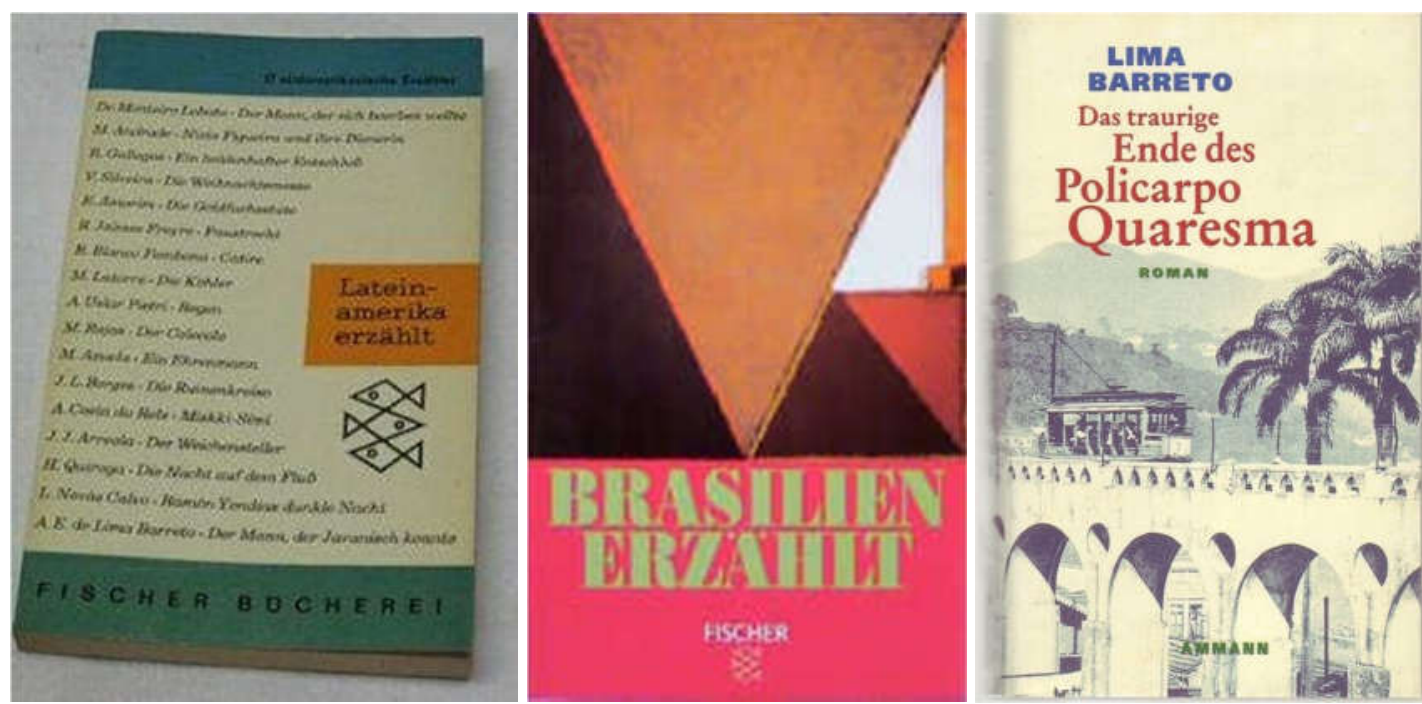

Figura 1: Lateinamerika erzählt Brasilien erzählt / Das Traurige Ende des Policarpo Quaresma
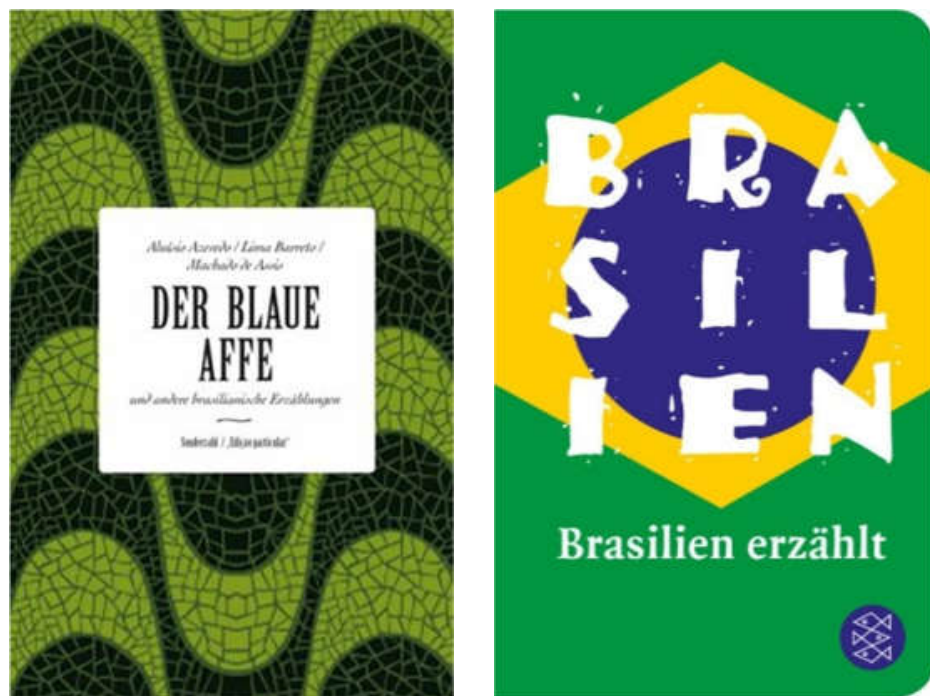

Brasilien erzählt

Figura 2: Der blaue Affe und andere brasilianische Erzählungen / Brasilien erzählt 


\subsection{Catalão / Chinês}
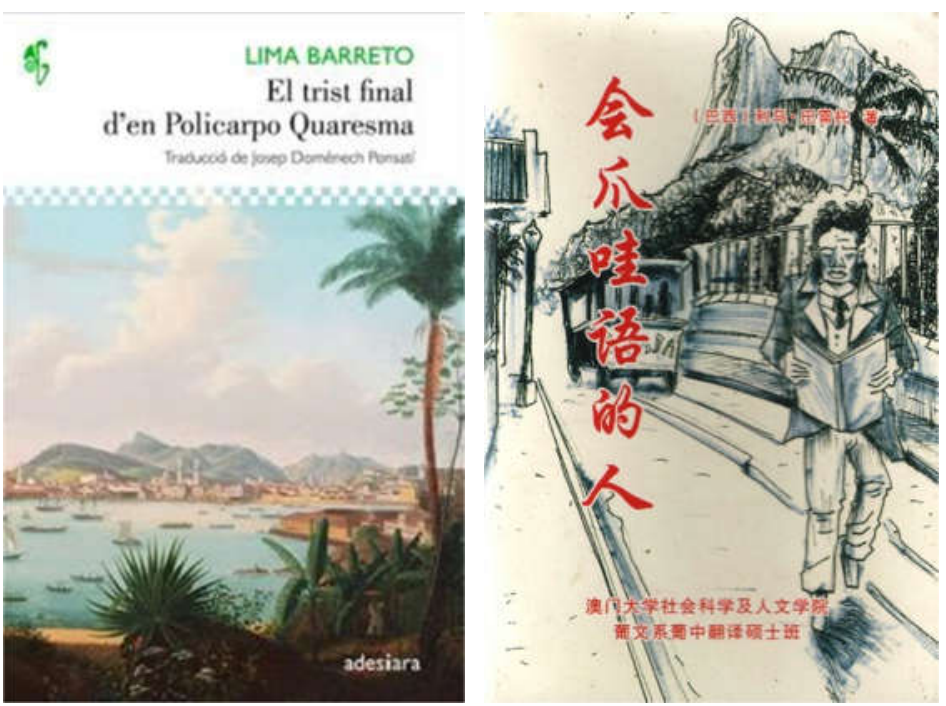

Figura 3: El trist final d'en Policarpo Quaresma / 会爪哇语的人

\subsection{Espanhol}
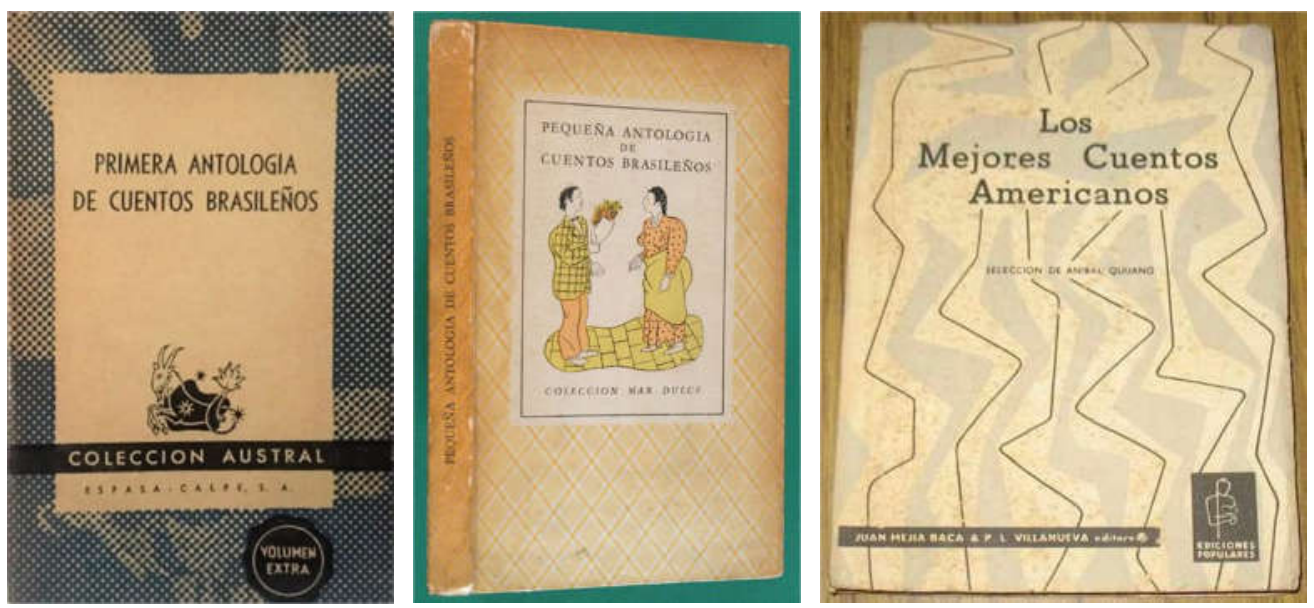

Figura 4: Primera antología de cuentos brasileños / Pequeña antologia de cuentos brasileños / Los mejores cuentos americanos 

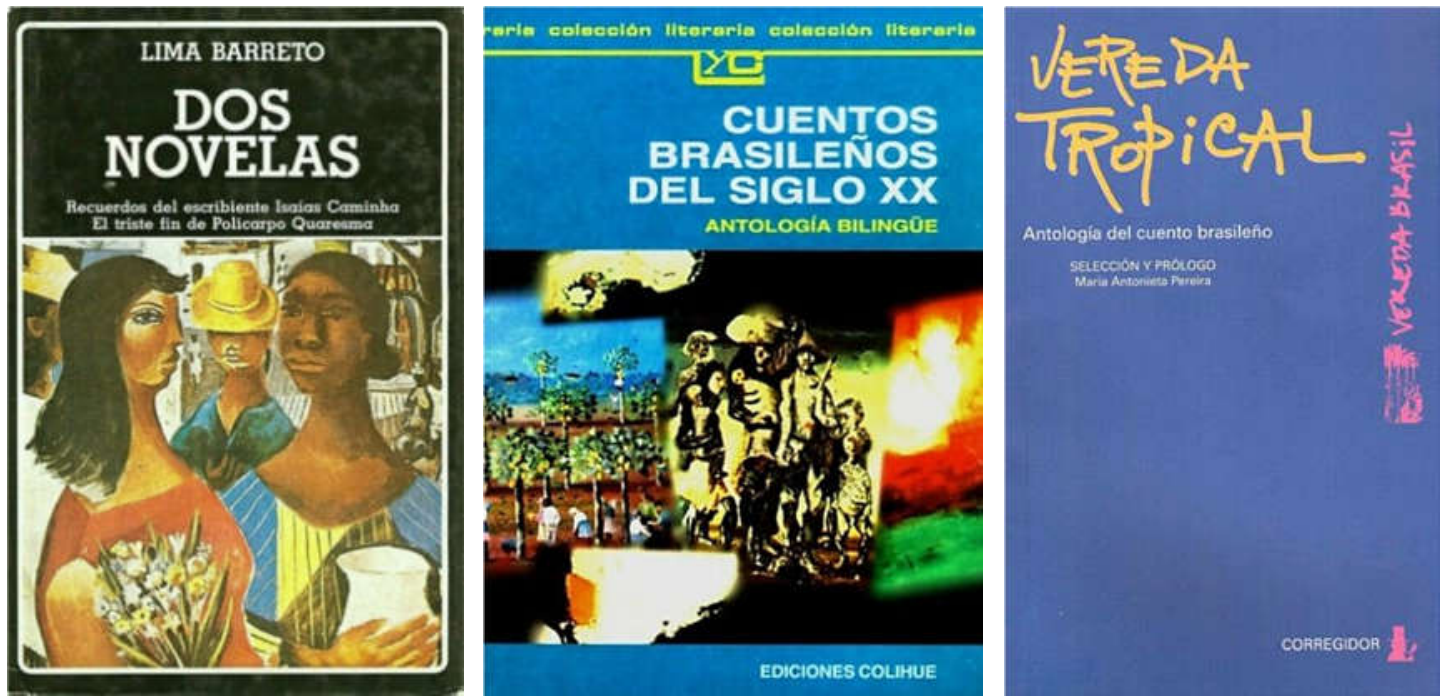

Figura 5: Dos Novelas / Cuentos brasileños del siglo XX / Vereda tropical
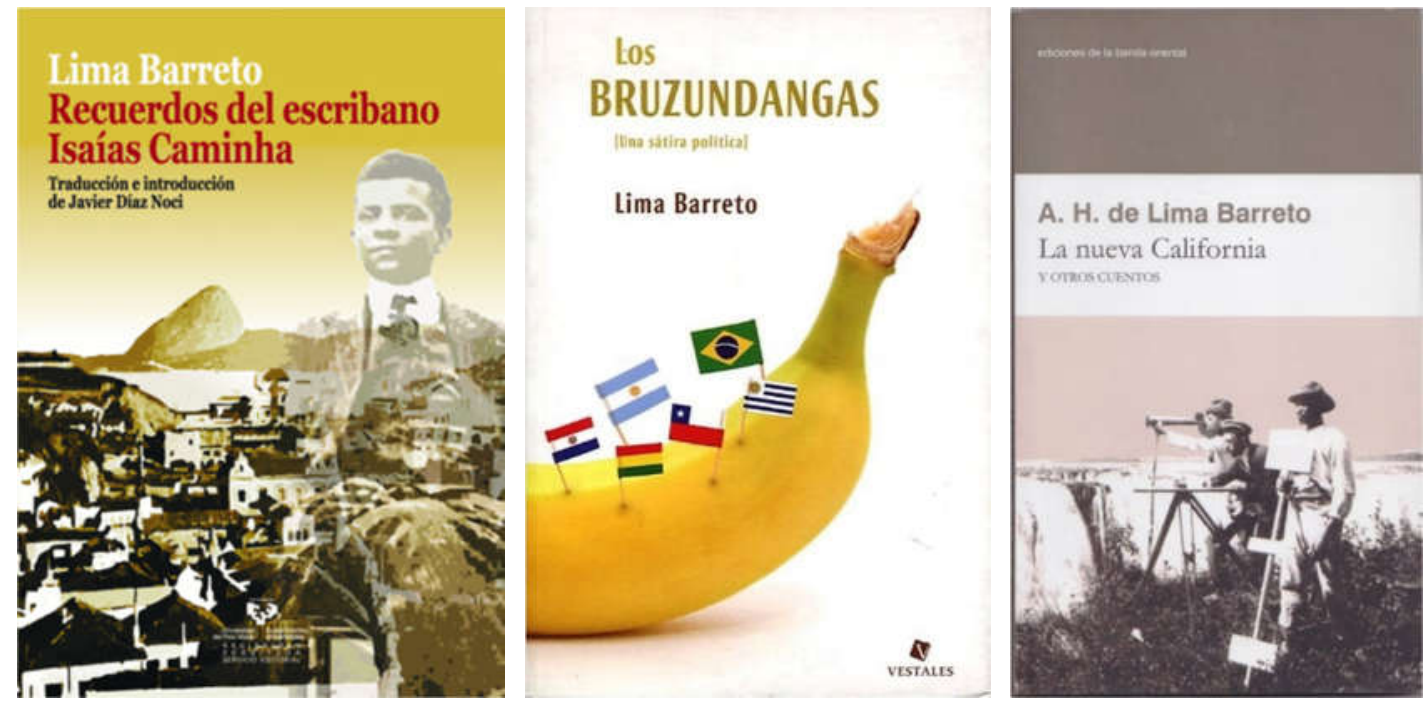

Figura 6: Recuerdos del escribano Isaías Caminha / Los bruzundangas La nueva California
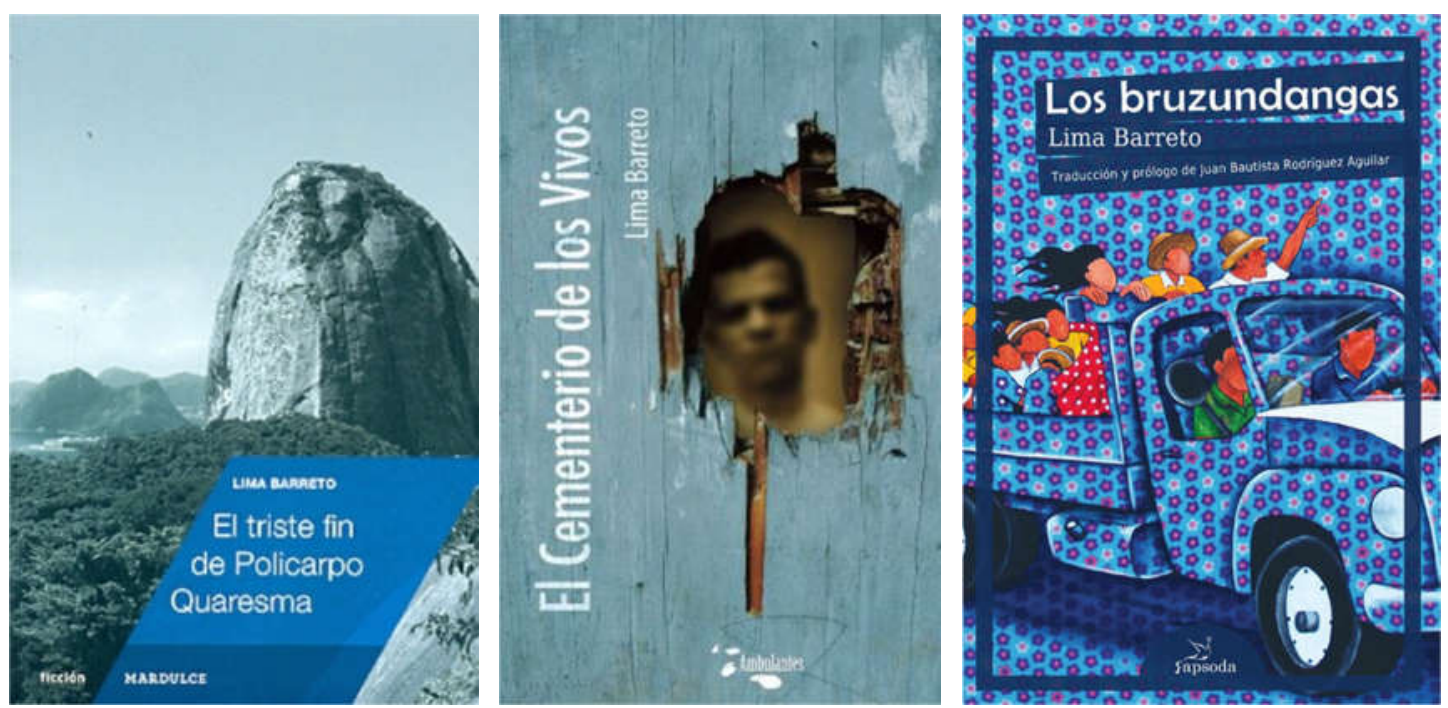

Figura 7: El triste fin de Policarpo Quaresma / El cementerio de los vivos / Los Bruzundangas 


\subsection{Esperanto}

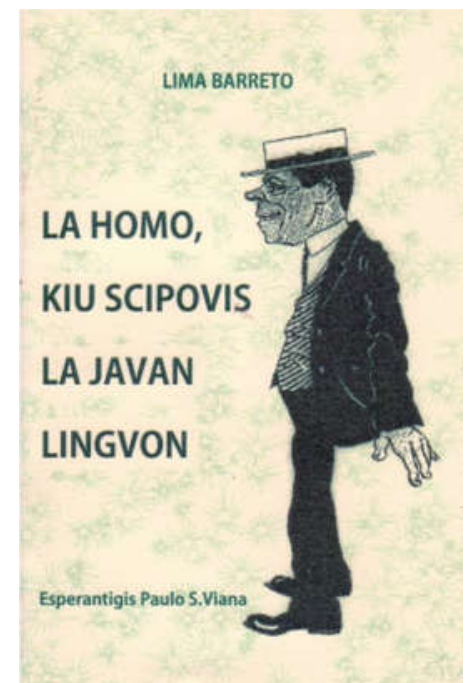

Figura 7: La Homo, kiu scipovis la javan lingvon

\subsection{Francês}
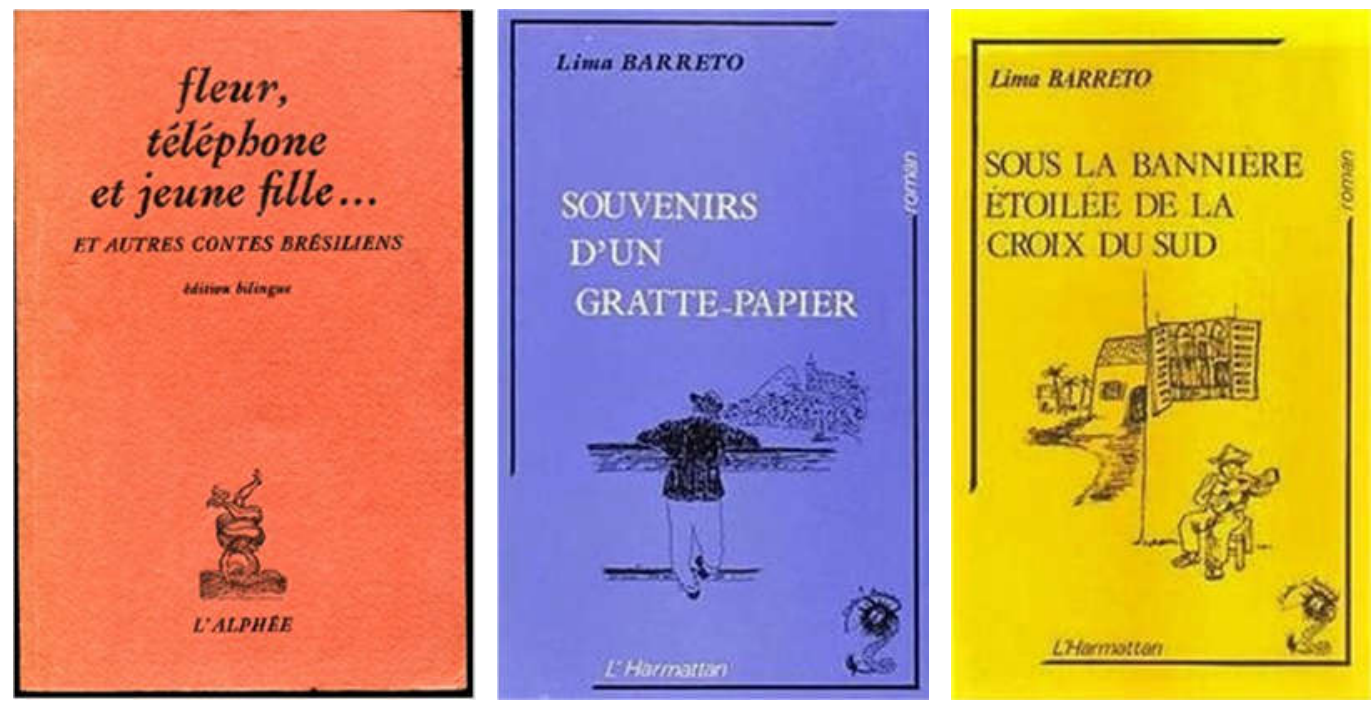

Figura 8: Fleur, téléphone et jeune fille / Souvenirs d'un Gratte-Papier / Sous la Banniere Etoilèe dela Croix du Sud 


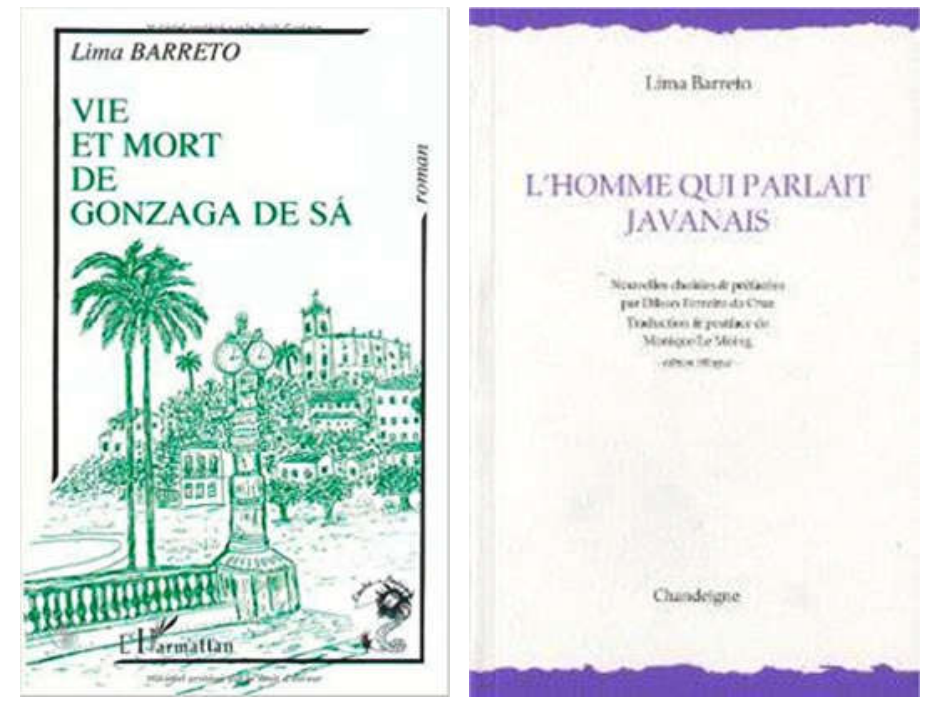

Figura 9: Vie et Mort de Gonzaga de Sá / L'Homme qui parlait javanais

\section{6 Grego}

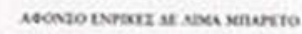

\section{H véa}

Kaגı̣ópvia

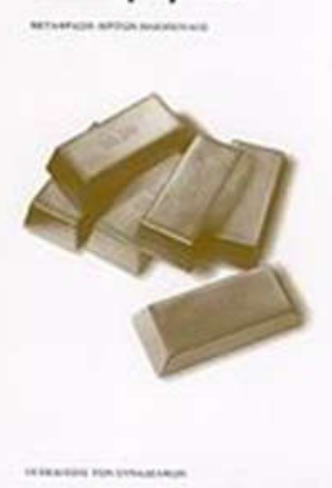

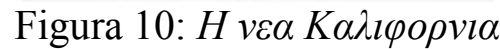




\section{7 Inglês}
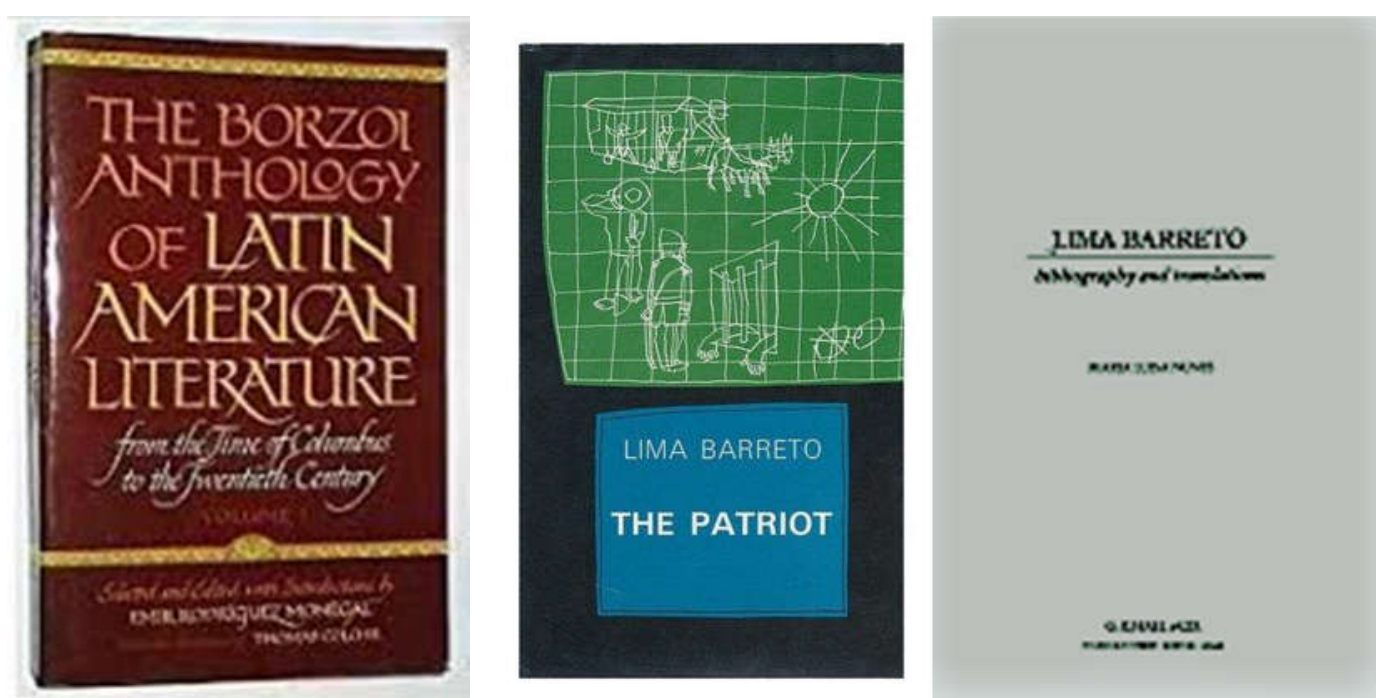

Figura 11: The Borzoi Anthology of Latin American Literature / The Patriot / Lima Barreto
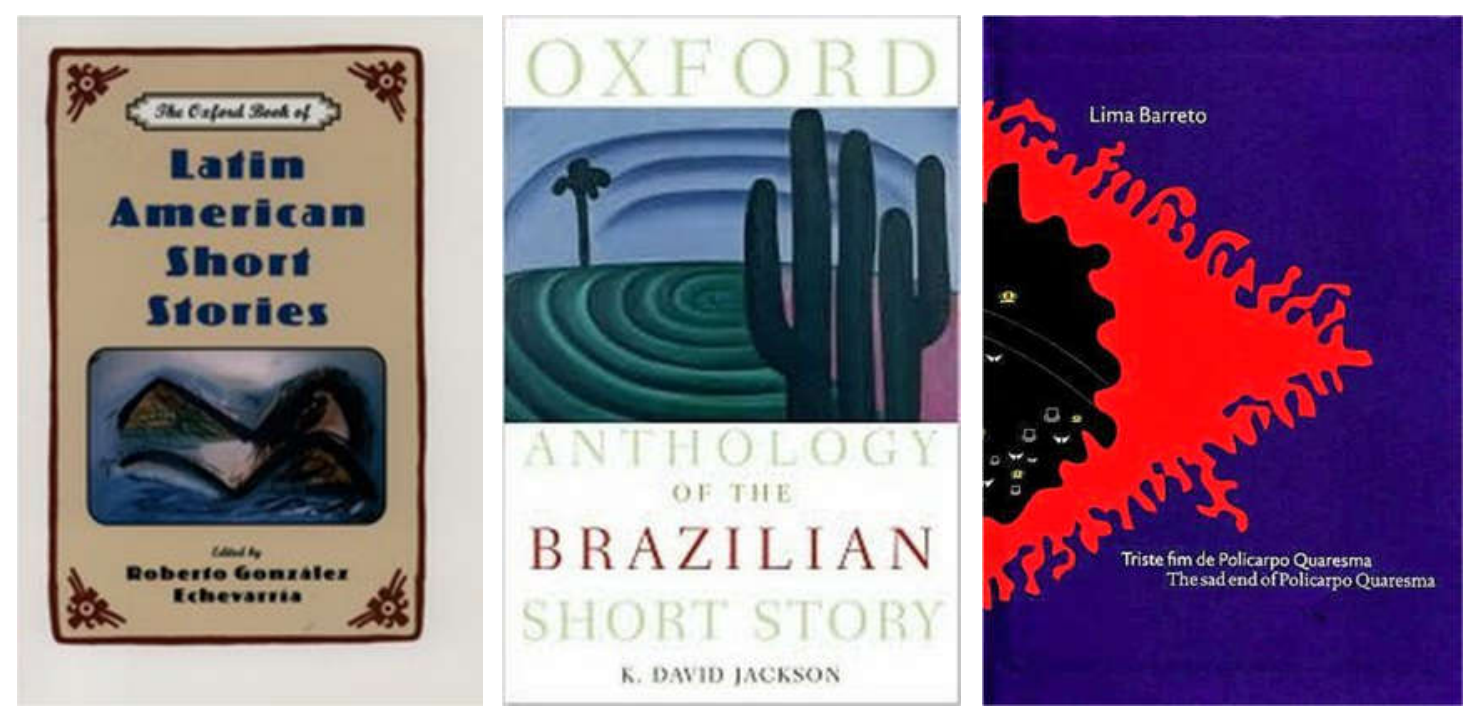

Figura 12: The Oxford Book of Latin American short stories / Oxford Anthology of the Brazilian Short Story / The sad end of Policarpo Quaresma 

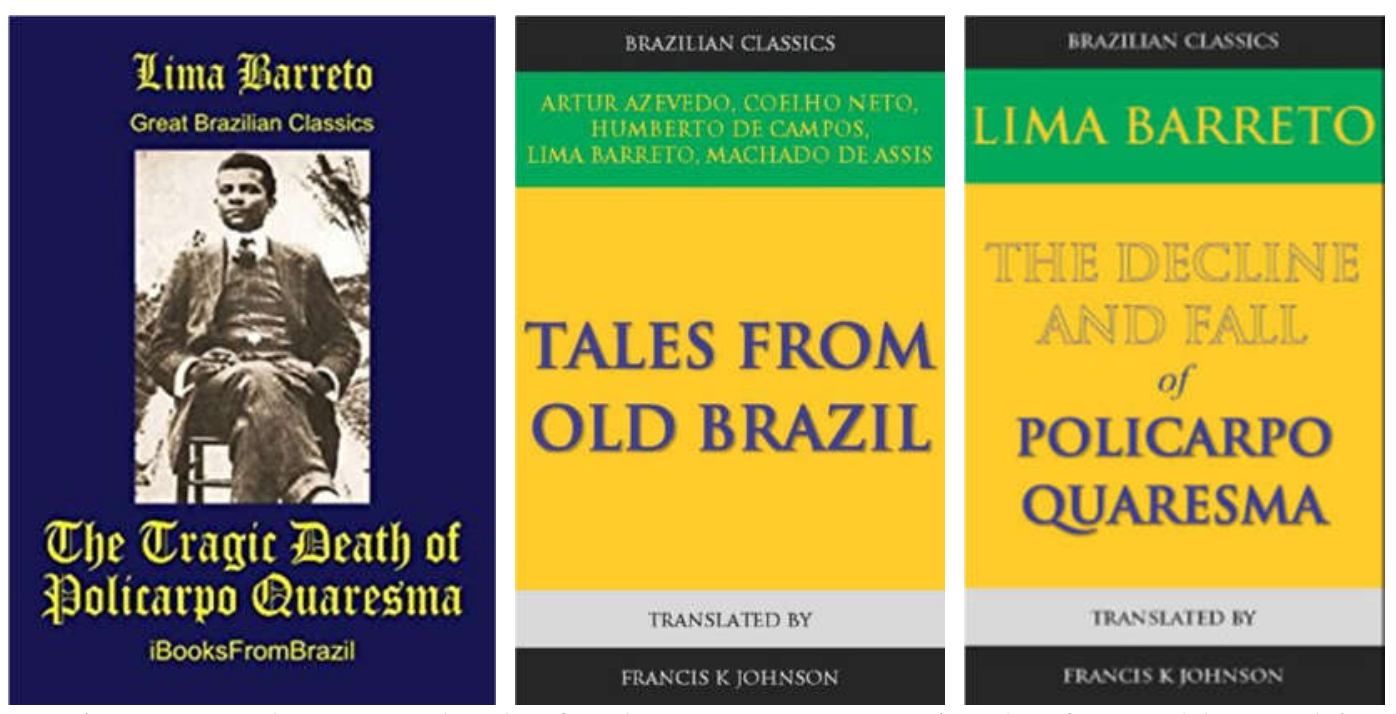

Figura 13: The tragic death of Policarpo Quaresma / Tales from Old Brazil / The decline and fall of Policarpo Quaresma

2. 8 Italiano

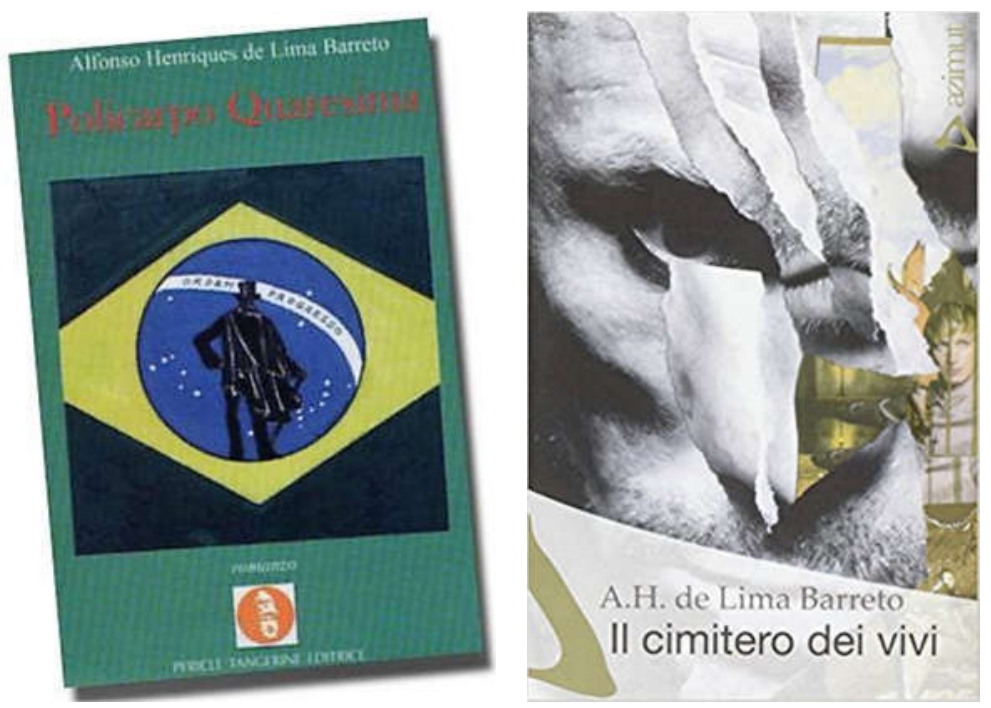

Figura 14: Policarpo Quaresima / Il cimitero dei vivi / 


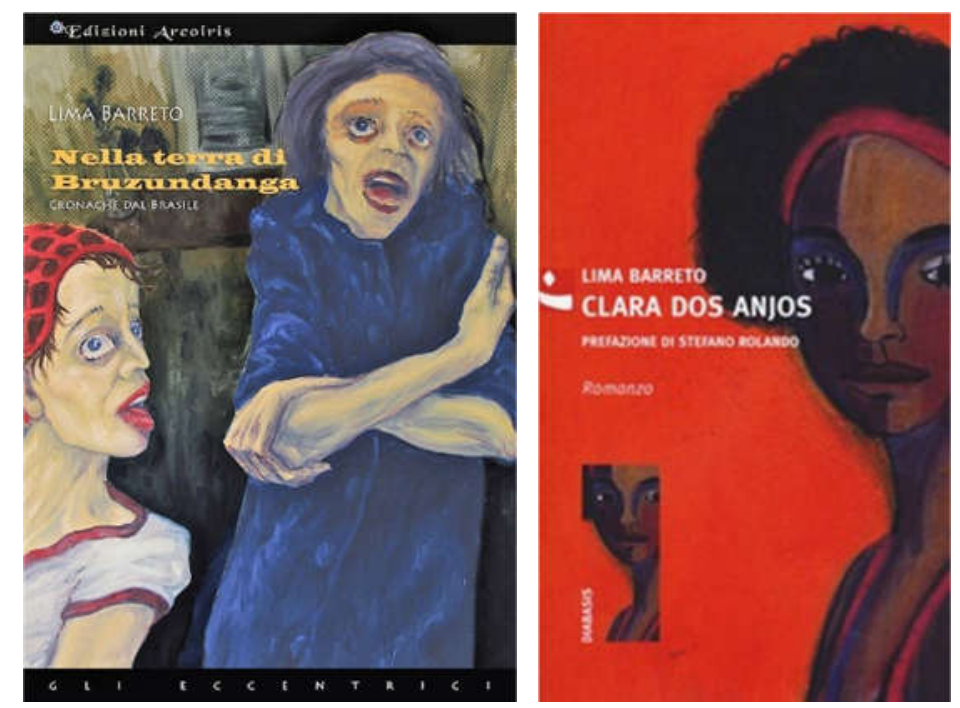

Figura 15: Nella terra di Bruzundanga / Clara dos Anjos

\subsection{Polonês / Romeno}
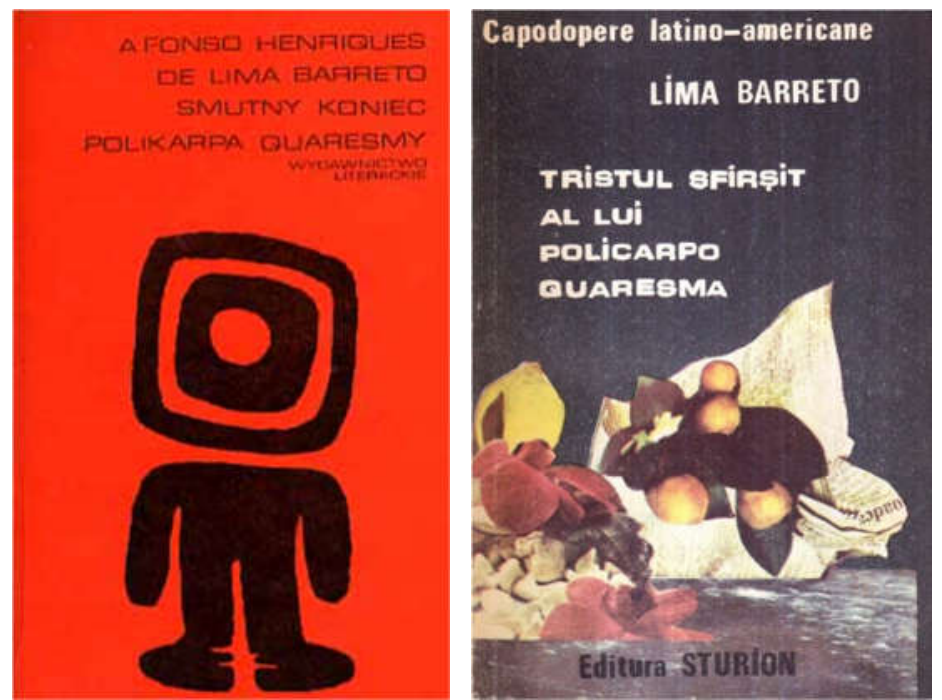

Figura 16: Smutny konied Polikarpa Quaresmy / Tristul sfirsşit al lui Policarpo Quaresma 
2. 10 Russo
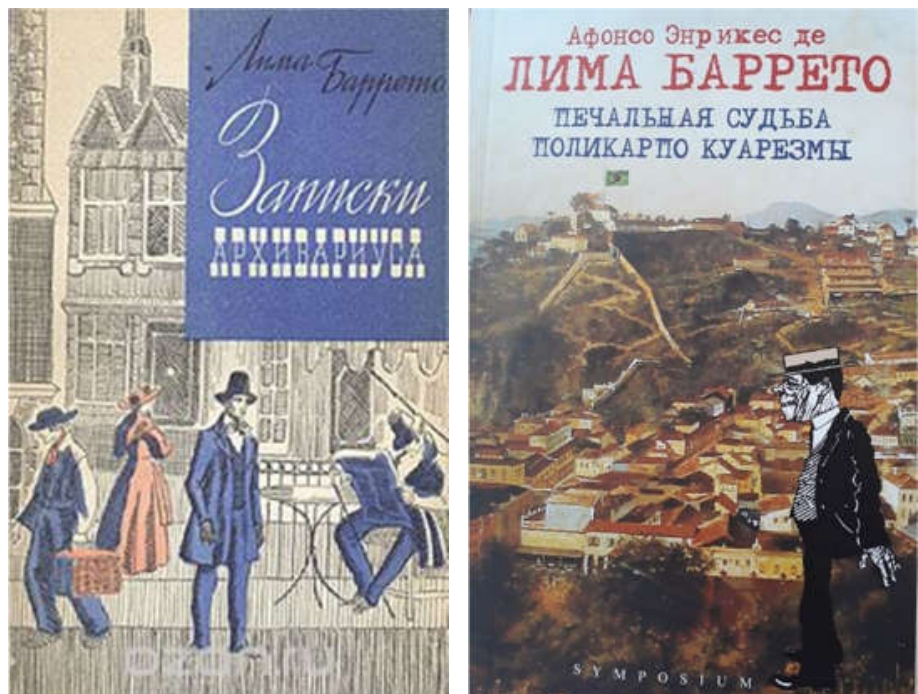

Figura 17: Записки Архивариуса / Зщудшсфкзщ Йгфкуыььф

\subsection{Sueco/Tcheco}
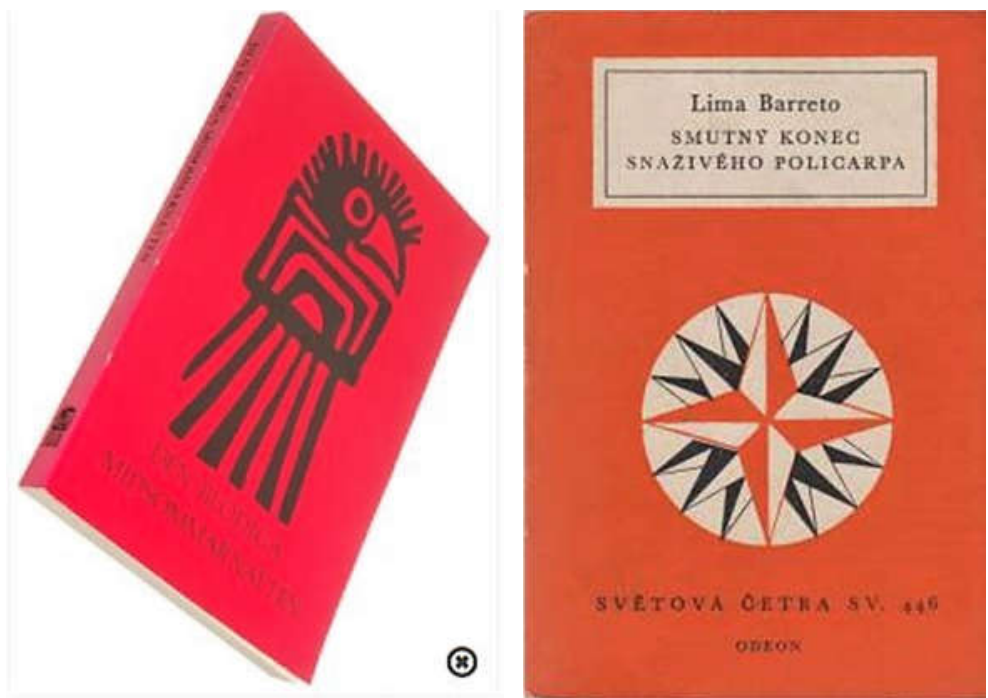

Figura 18: Den blodiga midsommarnatten / Smutný konec snazivého Policarpa

Denise Bottmann DBottmann@gmail.com

Recebido em: 9/9/2017 Aceito em: 12/2/2018 Publicado em Abril de 2018 